\title{
TECNOLOGIAS DA INFORMAÇÃO E COMUNICAÇÃO NO ENSINO A DISTÂNCIA PARA A CAPACITAÇÃO DE SERVIDORES PÚBLICOS
}

\author{
TECNOLOGÍAS DE INFORMACIÓN Y COMUNICACIÓN EN EDUCACIÓN A \\ DISTANCIA PARA LA FORMACIÓN DE SERVIDORES PÚBLICOS
}

\section{INFORMATION AND COMMUNICATION TECHNOLOGIES IN DISTANCE EDUCATION FOR THE TRAINING OF PUBLIC SERVANTS}

\author{
Vanessa Alcântara Cardoso MENDES ${ }^{1}$ \\ Kellcia Rezende SOUZA ${ }^{2}$
}

RESUMO: Neste artigo teve-se como objetivo investigar se os cursos de qualificação disponibilizados pelo Departamento de Educação e Cultura do Exército - DECEx - aos servidores do Exército Brasileiro (EB) por meio da modalidade em Educação a Distância (EaD) agregam benefícios pessoais e profissionais aos cursistas. Para tanto, utilizou-se a abordagem metodológica qualitativa para subsidiar a pesquisa bibliográfica e em campo. $\mathrm{O}$ instrumento de coleta de dados foi o questionário com perguntas do tipo abertas. Foi possível constatar que os participantes da pesquisa obtiveram benefícios significativos para a qualificação por meio da ampliação do acesso a essas oportunidades de qualificação profissional. Por outro lado, evidenciou-se, também, dificuldades para o alcance das competências necessárias para a utilização de tecnologias da informação e comunicação como ferramentas pedagógicas efetivamente a serviço da capacitação dos servidores e, consequentemente, na melhoria do serviço público para a sociedade.

PALAVRAS-CHAVE: Educação a distância. Instituição pública federal. Qualificação profissional.

RESUMEN: El objetivo de este artículo fue investigar si los cursos de calificación puestos a disposición por el Departamento de Educación y Cultura del Ejército - DECEx - a los servidores del Ejército Brasileño (EB) a través de la modalidad Educación a Distancia (EaD) agregan beneficios personales y profesionales a la cursistas. Para ello, se utilizó un enfoque metodológico cualitativo para apoyar la investigación bibliográfica y de campo. El instrumento de recolección de datos fue el cuestionario con preguntas abiertas. Se pudo constatar que los participantes de la investigación obtuvieron importantes beneficios para la calificación a través de la ampliación del acceso a estas oportunidades de calificación profesional. Por otro lado, también hubo dificultades para lograr las habilidades necesarias para el uso de las tecnologías de la información y la comunicación como herramientas

\footnotetext{
1 Universidade Federal da Grande Dourados (UFGD), Dourados - MS - Brasil. Professora Substituta na Faculdade de Educação dos Cursos de Graduação. Mestre em Teoria e Pesquisa do Comportamento (UFPA). ORCID: https://orcid.org/0000-0003-4745-6446 E-mail: alcantaracardoso@gmail.com

${ }^{2}$ Universidade Federal da Grande Dourados (UFGD), Dourados - MS - Brasil. Professora Adjunta na Faculdade de Educação. Doutorado em Educação Escolar (UNESP). ORCID: https://orcid.org/0000-0002-8663-4615. Email: kellcia@hotmail.com
} 
pedagógicas que sirvan eficazmente a la formación de los servidores públicos y, en consecuencia, a la mejora del servicio público para la sociedad.

PALABRAS CLAVE: Educación a distancia. Institución pública federal. Calificación profesional.

ABSTRACT: The objective of this article was to investigate whether the qualification courses made available by the Department of Education and Culture of the Army - DECEx - to the servers of the Brazilian Army (EB) through the Distance Education (EaD) modality add personal benefits and professionals to the trainees. To do this, a qualitative methodological approach was used to support the bibliographic and field research. The data collection instrument was the questionnaire with open questions. It was found that the research participants gained significant qualification benefits through expanding access to these professional qualification opportunities. On the other hand, there were also difficulties in achieving the necessary skills for the use of information and communication technologies as pedagogical tools that effectively serve the training of public servants and, consequently, the improvement of public service for the society.

KEYWORDS: Distance education. Federal public institution. Professional qualification.

\section{Introdução}

Podemos considerar que décadas atrás o universo do conhecimento e do trabalho conservavam conexões e objetivos distintos. Entretanto, o período pós segunda guerra mundial, o conhecimento e o trabalho findaram a ter um relacionamento mais profundo e até de co-dependência. Neste cenário, a educação ganhou notoriedade década a década, sendo tema prevalente nos debates sobre políticas públicas e cidadania, aparecendo nestas discussões como alicerce para uma sociedade melhor. Entretanto, temos vivenciado momentos difíceis com o passar de alguns anos, pois cada vez mais a sociedade brasileira, tem se deparado com cortes governamentais nos investimentos para a educação, assim como reduções do alcance das políticas públicas educacionais já implementadas (GADELHA, 2017).

Em contexto semelhante ao da educação, a informação também ganhou espaço considerável na sociedade, nos debates e nas necessidades do desenvolvimento dos países. Assim, educação e informação, precisaram urgentemente da tecnologia para conseguirem estar em condições de acessibilidade para a população. Neste cenário, a educação e suas modalidades em consonância com o advento tecnológico, têm sido cada vez mais buscadas por setores econômicos, governos e sociedade em geral. 
Portanto, investimentos em educação passam a ser frequentemente mais necessários e deveriam ser prioritários, não somente na sociedade brasileira, como, no mundo, concretizando, assim, uma metamorfose nas práticas sociais, econômicas e culturais. Apesar dessa aclamação por mais investimentos para a educação, as políticas públicas educacionais implementadas não têm sido ampliadas, pois, para tanto, não bastam as formulações destas políticas, mas a manutenção e investimentos sólidos e contínuos (GADELHA, 2017).

Projetos educacionais inovadores, a inserção das Tecnologias Digitais de Informação e Comunicação e os fortes debates sobre a necessidade de investimentos e manutenção de verbas nessas áreas, são pautas primordiais para o desenvolvimento de um país e a sua inserção no cenário global. Uma educação que tenha prioridade na agenda política, onde novas modalidades e metodologias devem ser adotadas para que auxiliem na melhora dos indicadores educacionais (ARAÚJO, 2013).

Neste cenário, a Educação a Distância, sendo ela uma modalidade de educação segundo a Lei de Diretrizes e Bases da Educação Nacional (LDB) n. 9.394/1996, vem para a sociedade como uma das alternativas factíveis para a ampliação da oferta educacional. Nessa vertente, é importante registrar que as transformações no mundo do trabalho oriundas, principalmente, do avanço tecnológico tem exigido o desenvolvimento dos/as profissionais qualificados. No Brasil, no âmbito das instituições públicas, cada vez mais tem crescido o aumento de ofertas de cursos de capacitação com o intuito de oportunizar um espaço formativo que permita ampliação de conhecimentos e competências técnicas. Desse modo, essa demanda tem sido atendida com a oferta de cursos na modalidade EaD (RANZINI; BRYAN, 2017).

Em um estudo realizado por Mourão (2009), que teve por objetivo mapear oportunidades de qualificação profissional tanto em instituições públicas, quanto privadas, verificando quais delas oferecem mais oportunidades de qualificação, observou-se que nas 1.150 instituições pesquisadas, cerca de $60 \%$ delas oportunizam a qualificação dos funcionários, principalmente as instituições localizadas nas regiões Sul e Sudeste do Brasil.

Assim, denota-se que a utilização de ferramentas e metodologias educacionais aliadas as tecnologias de informação e comunicação estão mais presentes nos processos de formação, tanto nas instituições públicas, quanto nas privadas. Esses espaços formativos visam oferecer oportunidades de qualificação aos funcionários, compreendendo que a educação é um pilar necessário para o desenvolvimento profissional. Para Ranzini e Bryan (2017, p. 419), “a capacitação e formação de servidores públicos é tema que vem ganhando maior expressividade no Brasill”. As ampliações de configurações das funções do Estado tem, cada 
vez mais, demandado melhorias na prestação de serviços, o que requer maior qualificação de servidores públicos.

O Exército Brasileiro (EB), enquanto instituição pública do poder executivo, se insere neste processo de formação e qualificação de seus servidores, dando atenção ao uso das tecnologias. O EB possui uma responsabilidade, não somente com a proteção do território nacional, mas também em realizar essa proteção com inteligência, além da força físiológica. Dentre diversos departamentos bélicos e comunicacionais, essa instituição possui o Departamento de Educação e Cultura do Exército (DECEx).

O DECEx vem, ao longo de sua criação, prosperando em termos pedagógicos, onde um de seus princípios é o de proporcionar educação continuada por meio de permanente capacitação profissional dos seus integrantes, servindo-se da modalidade de Educação a Distância para isto (BRASIL, 2015).

Esta instituição federal, não podendo estar obsoleta no que diz respeito aos progressos tecnológicos, principalmente os tecnológicos educacionais e pedagógicos, utiliza-se da modalidade de Educação a Distância para garantir, de acordo com suas leis e regulamentos próprios, nas seguintes áreas: (1) educação militar; (2) normas do ensino por competências; (3) gestão de pessoas; (4) avaliação e desenvolvimento da educação superior militar (BRASIL, 2018).

Assim, para o Exército Brasileiro, a Educação a Distância surge como uma opção para que seja oferecido qualificação, empregando os benefícios da EaD. Frente ao exposto, a presente pesquisa tem como intuito investigar se os cursos de qualificação oferecidos pelo DECEx no ano de 2019, por intermédio da Educação a Distância, trouxeram benefícios aos cursistas e a referida instituição pública. Para tanto, foi realizado a partir de uma abordagem qualitativa uma pesquisa bibliográfica e em campo, no qual recorreu a aplicação do questionários com os/as servidores/as do EB de $28^{\circ}$ Batalhão de Logística de Dourados-MS.

\section{A capacitação de servidores/as públicos no Exército Brasileiro}

A qualificação profissional é um ponto almejado tanto pelo trabalhador, quanto pela empresa e/ou órgão púbico. Qualificação acarreta ganho para ambos. Gerir pessoas no âmbito do trabalho tem-se tornado um imenso desafio na atualidade, tendo que gerenciar não só pessoas, mas o tempo delas. Alguns elementos como a terceirização, novas maneiras de gestão e o avanço da tecnologia têm incitado mudanças expressivas para as organizações e para o trabalho, exigindo qualificação e atualizações constantes (MOURÃO, 2009). 
Aires et al. (2014) destacam que a qualificação do trabalhador aumenta a produtividade e o potencial do serviço oferecido. A finalidade não está apenas em adequar o trabalhador às exigências do mercado, mas, também, em contribuir para a oferta de serviços que trarão qualidade à sociedade.

\begin{abstract}
Os investimentos públicos em capacitação de pessoal têm crescido a partir dos anos 1990, assim como a avaliação concreta dos resultados desses recursos, visando comprovar se a capacitação tem de fato agregado valor ao serviço público [...]. Isto porque o avanço tecnológico e o rearranjo das fronteiras econômico-culturais advindas da globalização têm acelerado o grau de mudanças, assim como a complexidade instalada no interior das organizações, fazendo com que haja uma necessidade de qualificação daqueles que participam diretamente do funcionamento do Estado e dos que tomam decisões e as influenciam (AIRES et al., 2014, p. 1008).
\end{abstract}

Neste contexto, a modalidade EAD ganha força nesse novo processo educacional de formação para qualificação do trabalho, tendo sido uma modalidade educacional bem recorrente na oferta da capacitação e qualificação dos/as servidores/as públicos Brasil.

Tendo a EAD nascido a partir da necessidade de unir o trabalho com a capacitação e qualificação profissional, essa percepção de necessidade de uma formação continuada dentro do Exército vem desde o ano de 1811, onde foi criada "A Real Academia Militar", vista como um símbolo na história da educação militar. Nesta Real Academia já se aplicava os "estudos domiciliares", que são indicadores do que hoje associamos a $\mathrm{EaD}$ e até mesmo ao ensino remoto (SOUZA; ROCHA, 2017).

Albuquerque (2011), em sua pesquisa, constata que o início da EaD no EB é no século XVII. Na referida pesquisa, a autora aponta que já havia um material didático para estudos na residência, cujo material tinha como objetivo instruir o EB na arte militar e, também, com os conhecimentos de aritmética, geometria, artilharia entre outros. Essa era uma das opções de capacitação, além daquelas que aconteciam no modelo presencial.

A partir da propagação do ensino por correspondência no século XX e, mais tarde, dos cursos a distância, o EB exerceu, por meio desta modalidade, cursos de qualificação dos seus servidores públicos. De acordo com a Portaria $n^{\circ}$ 236-DECEx/2018, foram aprovadas as "Instruções Reguladoras do Sistema de Educação Superior Militar do Exército". Neste documento está normatizado todo Sistema de Educação Superior Militar do Exército SESME. A imensidão do Brasil, as limitações financeiras e a dificuldade de uma regularidade desses servidores públicos nos cursos presenciais, concorreram para uma maior procura da EaD como uma modalidade de ensino que oferecesse possibilidades mais adaptáveis às diversas realidades para a formação e qualificação profissional. 
A EB brasileiro dispõe de uma normativa específica sobre ensino em sua instituição, que está regulamentada na Lei n. 9.786/1999, no qual versa em seu artigo n. 1 sobre a finalidade do Ensino no EB, que corresponde em qualificar recursos humanos para a ocupação de cargos e para o desempenho de funções previstas, na paz e na guerra, em sua organização (BRASIL, 1999).

Além disso, o EB possui um Departamento de Educação e Cultura - DECEx - criado pelo Decreto Presidencial $n^{0} 6.710 / 2008$, que configura em uma instância que tem como atribuição planejar, organizar, dirigir e controlar, em nível de direção setorial, as atividades relativas a assuntos educacionais e culturais no EB (BRASIL, 2008). As principais funções deste Departamento são:

- Qualificar recursos humanos para a ocupação de cargos e desempenho de funções nas Linhas de Ensino Militar Bélico, de Saúde e Complementar;

- Proporcionar a educação continuada por meio da permanente capacitação profissional dos integrantes do Sistema de Ensino do Exército (SEE);

- Oferecer a educação preparatória e assistencial no EB buscando apoiar a família militar nas melhores condições;

- Modernizar e racionalizar as atividades afetas à educação, cultura, educação física, aos desportos e à pesquisa científica no âmbito do Exército;

- Ampliar a integração do SEE na esfera de suas atribuições com sistemas similares;

- Preservar e divulgar o patrimônio histórico e cultural, material e imaterial do EB;

- Projetar a imagem do EB, em âmbito nacional, a partir dos seus valores culturais;

- Desenvolver a prática da atividade física e do desporto no Exército;

- Promover ações que proporcionem ao EB uma atuação destacada em competições desportivas, em nível nacional e internacional;

- Desenvolver a produção científica nas áreas de defesa, ciências militares, doutrina e pessoal;

- Contribuir com o processo de formulação e atualização do Sistema de Doutrina Militar Terrestre.

Para alcançar esses objetivos, o DECEx possui um Portal de Educação que é um espaço virtual com o objetivo de ampliar e aperfeiçoar a Educação Militar. Tais objetivos foram estão presentes no Planejamento Estratégico do Exército (PEEx), onde consta a meta 12 de "Implantar um Novo Sistema de Educação e Cultura", sendo que a estratégia para este objetivo é a “Atualização do Sistema de Educação e Cultura” (BRASIL, 2015). 
O Portal da Educação é a resposta ao planejamento educacional da instituição presente no instrumento de planejamento intitulado "Diretriz de Educação e Cultura do Exército Brasileiro 2016-2022”. Esse documento também definiu as diretrizes de EaD para o EB, que compreende duas finalidades:

I - consolidar a Educação a Distância (EAD) como modalidade educativa no Sistema de Ensino do Exército (SEE), em consonância com o Plano Estratégico do Exército (PEEx 2016-2019) e o Projeto Político-Pedagógico da Instituição; e

II - definir as áreas de responsabilidade dos órgãos envolvidos no planejamento dos eventos de capacitação em EaD (BRASIL, 2015).

A consolidação da $\mathrm{EaD}$ no $\mathrm{EB}$ concretiza o objetivo estratégico de ampliar e consolidar a implantação do Ambiente Virtual de Educação e Cultura na instituição, visando, desse modo:

I - proporcionar aos integrantes do EB, servindo no Brasil ou no exterior, a capacitação nas áreas de interesse da Força e, até mesmo, nas áreas de interesse individual, quando conveniente para a Instituição;

II - proporcionar, aos dependentes dos integrantes do EB, servindo no Brasil ou no exterior, a continuidade de estudo nos ensinos fundamental e médio, de acordo com a legislação em vigor;

III - propiciar a articulação entre os processos formativos presencial e a distância, atendendo aos padrões de qualidade do ensino militar;

IV - constituir uma identidade pedagógica para a EAD, por meio de ações educativas fundamentadas em dinâmicas inovadoras e efetivas;

$\mathrm{V}$ - promover a oferta de eventos de capacitação de curta duração, cujas competências instrumentais ou de fundamentação sejam requeridas para o exercício dos cargos ou das funções previstos na estrutura organizacional do Exército; e

VI - consolidar o Centro de Educação a Distância do Exército (CEADEx) como uma organização militar (OM), com as missões de capacitar recursos humanos para atuar na modalidade de EAD e de coordenar e de orientar a execução dessa modalidade no âmbito do Exército (BRASIL, 2015).

Evidencia-se que o EB não só dispõe de regulamentações e instrumentos de planejamento que versam sobre o seu sistema de ensino como, também, um departamento específico com essa finalidade, no qual assegura um portal de educação onde está hospedado sua Plataforma Virtual de Aprendizagem que disponibiliza cursos na modalidade a distância e semipresencial. Essa condição permite com que a instituição estabeleça uma política educacional de capacitação e qualificação dos seus servidores/as. 


\section{Resultados}

A escolha do $28^{\circ}$ Batalhão de Dourados-MS como lócus de pesquisa está associado a longevidade do EB, pois trata-se de uma das mais antigas do serviço público, bem como, da institucionalização de uma política educacional de formação que apresenta normativas específicas, bem como, infraestrutura e orçamentos próprios para essa finalidade.

A pesquisa em campo foi realizada por meio da aplicação de um questionário, no qual haviam quatro questões abertas: (1) "Qual curso você realizou na modalidade EaD ofertado pelo Exército Brasileiro?”; (2) "Liste os benefícios pessoais e profissionais que a participação no curso trouxe para você."; (3) "Liste as dificuldades que você encontrou em realizar o curso na modalidade EaD"; (4) "Liste as facilidades que você identificou em realizar o curso na modalidade EaD”. Os questionários foram destinados a duzentos e um/a servidores/as.

Dos duzentos e um que receberam o questionário, houve a devolutiva de cento e vintes e três servidores/as. Considera-se questionário válido aqueles que tiveram respostas às questões e não tinha identificação nem rasuras. O período de aplicação dos questionários ocorreu entre agosto a dezembro de 2019. Usamos como critério para seleção dos sujeitos aqueles/as que já tivessem participado de alguma capacitação e/ou qualificação oferecidas pelo EB por meio da modalidade de EaD.

Considerando o intuito de verificar se os cursos de qualificação ofertados pelo EB na trouxeram benefício aos servidores públicos cursistas, identifica-se que dos cento e um participantes da pesquisa, $74 \%$ já havia realizado um curso de formação $\mathrm{EaD}$, os demais $26 \%$ mais de um curso nesta modalidade, conforme gráfico 1:

Gráfico 1 - Participantes de cursos a distância

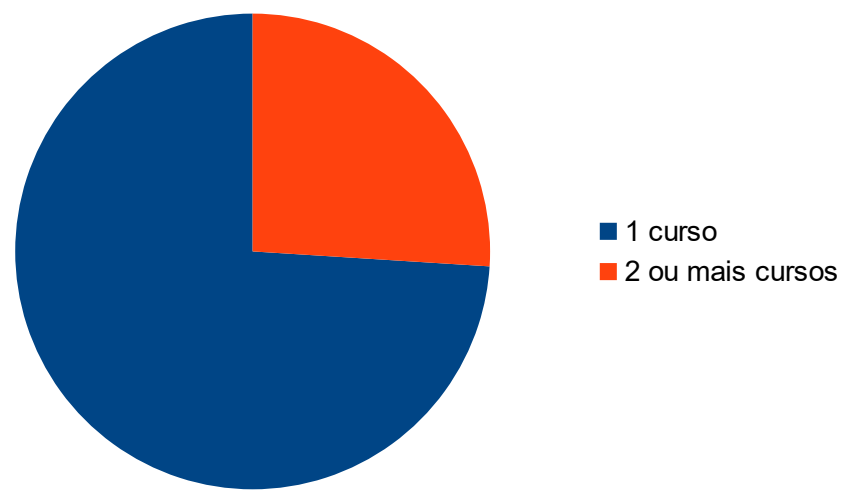

Fonte: Elaboração própria das pesquisadoras 
As novas exigências no perfil dos profissionais para atender às demandas sociais têm ordenado de maneira imperiosa, em termos de conhecimento e aprendizagem, profissionais conectados e abertos a outras possibilidades de capacitação para uma atuação de qualidade com atualizações e inovações na utilização tecnologias e metodologias pedagógicas (PERRENOUD, 2005). Tento em vista essa perspectiva, percebe-se, de acordo com os dados apresentados no gráfico 1 que ainda há uma pouca adesão aos cursos oferecidos pelo EB. Observa-se que a maioria realizou apenas um curso. Ao serem perguntados sobre os benefícios, tanto profissionais, quanto pessoais, os participantes responderam conforme Tabela 1:

Tabela 1 - Benefícios pessoais e profissionais destacados

\begin{tabular}{|c|c|}
\hline Benefícios Pessoais & Benefícios Profissionais \\
\hline Aumento do gosto pela leitura e aprendizagem & Conhecimento aprofundado da profissão \\
\hline Cultura em geral & $\begin{array}{l}\text { Aumento do potencial para contribuir com a Instituição } \\
\text { Pública }\end{array}$ \\
\hline Habilitação para promoções & $\begin{array}{l}\text { Ampliação do conhecimento, possibilitando ações em } \\
\text { diversos espaços na Instituição Pública }\end{array}$ \\
\hline Concentração e foco & $\begin{array}{l}\text { Conhecimento de áreas e setores específicos na } \\
\text { Instituição Pública }\end{array}$ \\
\hline $\begin{array}{l}\text { Utilização do conhecimento do curso na vida } \\
\text { pessoal. Exemplo: educação financeira }\end{array}$ & Maior conhecimento sobre assuntos militares \\
\hline Ser mais persistente & Melhoria no trabalho oferecido pela Instituição Pública \\
\hline Novas técnicas de ensino e aprendizagem & Conhecimento Institucional \\
\hline Melhoria na postura militar & Participar de missões no exterior \\
\hline Organização pessoal do tempo & $\begin{array}{l}\text { Aumento do conhecimento administrativo da } \\
\text { Instituição Pública }\end{array}$ \\
\hline $\begin{array}{l}\text { Facilidade em aprender por meio das Tecnologias } \\
\text { de informação }\end{array}$ & Preparo técnico para sucessão de cargos \\
\hline Atualização em tecnologias educacionais & \\
\hline
\end{tabular}

Fonte: Elaboração própria das pesquisadoras 
As exigências no perfil dos profissionais para atender às demandas sociais têm ordenado de maneira imperiosa, em termos de conhecimento e aprendizagem, servidores/as como formação para utilização de tecnologias, conduzindo-os para uma atuação sempre de qualidade (PERRENOUD, 2005). A qualificação profisssional na modalidade EaD tem como intenção uma prática educacional para o aprimoramento e desenvolvimento das competências necessárias ao profissional.

Apesar da maioria dos servidores terem realizados apenas um curso de formação em $\mathrm{EaD}$, conforme dados apresentados na Figura 1, os dados registrados na Tabela 1 sinalizam a identificação de diversos benefícios pessoais e profissionais identificados pelos participantes dos cursistas.

Ao serem questionados sobre as dificuldades na realização do curso, apenas $17 \%$ relataram não ter nenhum tipo de dificuldade, mas para 84\% é possível apontar algum tipo de dificuldade, como podemos observar na Tabela 2:

Tabela 2 - Dificuldades relatadas na realização do curso a distância

\begin{tabular}{|c|c|}
\hline \multirow{14}{*}{$\begin{array}{l}\text { Dif culdades } \\
\text { relatadas na } \\
\text { realização } \\
\text { do curso } \\
\text { EAD }\end{array}$} & Realização das provas \\
\hline & Tempo para dedicar aos estudos \\
\hline & Estudar no computador \\
\hline & Falta de adequação às novas tecnologias \\
\hline & Conciliar horas de estudos com at vidades diárias da função na OM \\
\hline & Pouco tempo para estudo devido função exercida \\
\hline & Acesso ao tutor para t rar as dúvidas era demorado \\
\hline & Falta de orientações específ čas \\
\hline & Demora para o esclarecimento das dúvidas \\
\hline & Plataforma de aprendizagem não intuit ia \\
\hline & Tráf ço intenso na realização das provas/mesmo horário todo Brasil \\
\hline & Internet de baixa velocidade \\
\hline & Conteúdos extensos e poucas horas para o estudo \\
\hline & Aprendizado somente teórico \\
\hline
\end{tabular}

Fonte: Elaboração própria das pesquisadoras

Observamos que, tanto o EB, quanto o servidor público militar têm interesse na capacitação. Entretanto, sendo ela na modalidade EaD, é importante observar que ainda há um número significativo de dificuldades que devem ser resolvidas para a garantia da qualidade do processo formativo, que foram evidenciadas pelos dados do Tabela 1. 
Há limitações na oferta de cursos em EaD no Brasil. Podem ocorrer algumas limitações tecnológicas, como a baixa capacidade do computador, a lentidão no acesso e a falta de flexibilidade do programa. Há, ainda, a considerar, as habilidades das pessoas para lidarem com a informática, com o computador em si, com a metodologia da EAD. Outra limitação diz respeito à questão cultural. No Brasil, por exemplo, valorizam-se os contatos face a face; é uma cultura fortemente relacional. O trabalho fisicamente solitário pode ser, então, uma limitação. Temos, também, de considerar que tarefas pouco claras e a ausência de feedback podem ser fatores que trazem limitações à EAD (VERGARA, 2007, p. 04).

Quando perguntados sobre as facilidades ao realizarem o curso na modalidade EaD apenas 4\% não encontraram nenhuma facilidade, enquanto que $96 \%$ relataram diversas facilidades e benefícios na realização dos cursos, conforme pode ser observado de modo detalhado no Tabela 3 a seguir.

Tabela 3 - Facilidades relatadas na realização de cursos a distância

\begin{tabular}{ll}
\hline Facilidades & Horário f exível \\
relatadas na & Diversidade de locais para estudo com acesso à Internet \\
realização & Poder escolher um ambiente tranquilo \\
do curso & Horário de estudo \\
EAD & Plataforma para t rar dúvidas \\
\hline & Baixo custo \\
\hline Uso das TI na aprendizagem \\
\hline Estudo no horário de expediente \\
\hline Poder estudar em casa \\
\hline Ajustar os horários de estudo \\
\hline Excelente material de apoio \\
\hline Apoio da OM para o aluno estudar \\
\hline Excelente Ambiente Virtual de Aprendiagem \\
\hline Ensino descomplicado \\
\hline Interação com outros alunos \\
\hline Prat cidade \\
\hline Provas on-line de múlt pla escolha \\
\hline
\end{tabular}

Fonte: Elaboração própria das pesquisadoras

De acordo com os dados do Tabela 3, podemos apontar que as seis finalidades da Diretriz de Educação a Distância para o Exército Brasileiro estão sendo cumpridas. Tal situação é um benefício não somente para o EB, mas, também, para a sociedade brasileira, onde se espera um retorno social dos investimentos realizados. Entretanto, tais benefícios deveriam ser mais concretos e difundidos por meio de políticas públicas. 
As formações de servidores no âmbito da gestão pública têm a responsabilidade de estimular, constantemente, a socialização do conhecimento e a partir dele garantir o desenvolvimento de competências profissionais dos quais asseguram a melhoria dos serviços prestados à população. Assim sendo, os dados mostram que o EB dispõe de uma institucionalização de processos formativos, que garante, marcos jurídicos, estrutura e orçamento específicos para essa finalidade. Trata-se de variáveis extremamente favoráveis para a consolidação de um sistema integrado de capacitação e qualificação dos seus servidores/as. Por outro lado, os limites apontados nas formações sinalizam a necessidade de uma política de monitoramento e avaliação desses cursos, o que irá permitir uma planejamento de ações direcionado a superação dos problemas identificados.

\section{Considerações finais}

Constatou-se, por meio da pesquisa, que os objetivos aos quais a $\mathrm{EaD}$ se propõe, dentro do EB, estão se refletindo na ampliação da qualificação dos seus servidores/as. Em relação aos desafios apresentados pelos participantes da pesquisa sobre as formações em $\mathrm{EaD}$, tais como: dificuldades no uso do computador e/ou outra ferramenta tecnológica; conciliar estudos com o trabalho e, até mesmo, limites de organização do seu tempo de estudos, demonstram entraves que também estão presentes em outras realidades formativas desse modalidade, dentre elas, as voltadas para o nível do Ensino Superior.

Considerando as dificuldades apontadas na pesquisa, salientamos a necessidade do EB e de outras instituições públicas criarem instrumentos de monitoramento e avaliação das formações ofertadas. Esses instrumentos oportunizam a identificação de problemas e a pontam indicadores para o planejamento das práticas pedagógicas.

É importante também considerar que os cursos de qualificação em formato $\mathrm{EaD}$ não substituem o sistema educacional com seus respectivos níveis de ensino, mas a mesma deve ser compreendida pelas gestões públicas como uma alternativa de possibilidade educacional para o desenvolvimento contínuo de trabalhadores/as. Sendo que, com o advento e popularização dos avanços das tecnologias de informação e comunicação, essa modalidade tem garantido o alcance cada vez maior do acesso aos processos formativos.

Neste sentido, a utilização da EaD se mostra como uma importante ferramenta para o desenvolvimento dos recursos humanos no EB, seja no processo de formação/capacitação e/ou no processo contínuo de conhecimento. Logo, é necessário cada vez mais que políticas institucionais e públicas compreenda a relevância desse espaço de aprendizagem para a 
constante qualificação dos servidores e, consequentemente, para as melhorias dos serviços públicos prestados a sociedade brasileira.

\section{REFERÊNCIAS}

AIRES, R. F. F. et al. Escolas de governo: o panorama brasileiro. Revista de Administração Pública, Rio de Janeiro, n. 48, v. 4, p. 1007-1027, jul./ago. 2014.

ALBUQUERQUE, A. C. C. “Atenção, sentido!”: a Educação a Distância está presente na caserna. 2011. 186 f. Dissertação (Mestrado) - Universidade do Estado do Rio de Janeiro, Rio de Janeiro, 2011.

ARAUJO, E. M. et al. A gestão da inovação na educação a distância. Gestão e produção, São Carlos, v. 20, n. 3, p. 639-651, 2013.

BRASIL. Decreto n. 3.182, de 23 de setembro de 1999. Regulamenta a Lei $n^{0} 9.786$, de 8 de fevereiro de 1999, que dispõe sobre o ensino no Exército Brasileiro. Brasília, 24 out 1999. Available at: http://www.planalto.gov.br/ccivil_03/decreto/D3182.htm. Access: 10 sep. 2020.

BRASIL. Decreto n. 5.484, de 30 de junho de 2005. Aprova a Política de Defesa Nacional, e dá outras providências. Brasília, 1 jul. 2005. Available at:

http://www.planalto.gov.br/ccivil_03/_ato2004-2006/2005/decreto/d5484.htm. Access: 10 sep. 2020.

BRASIL. Decreto n. 6.703, de 18 de dezembro de 2008. Aprova a Estratégia Nacional de Defesa, e dá outras providências. Brasília, 19 dez. 2008. Available at:

http://www.planalto.gov.br/ccivil_03/_ato2007-2010/2008/decreto/d6703.htm. Access: 10 sep. 2020.

BRASIL. Portaria n. 308-EME/2015. Aprova a Diretriz para a Implantação do Centro de Educação a Distância do Exército (EB20D-01.025). Boletim do Exército nº 48/2015. BrasíliaDF, 27 nov. 2015.

BRASIL. Portaria n. 236-DECEx, de 31/2018. Aprova as Instruções Reguladoras do Sistema de educação Superior Militar do Exército: Organização e Execução (EB60-IR57.002). Boletim do Exército nº 47/2018. Brasília-DF, 23 nov. 2018.

GADELHA, R. M. A. F. Educação no Brasil: desafios e crise constitucional. Revista Pesquisa e Debate, São Paulo. v. 28, n. 1 (51), jul. 2017.

MOURÃO, L. Oportunidades de Qualificação Profissional no Brasil: Reflexões a partir de um Panorama Quantitativo. Revista de Administração Contemporânea, v. 13, n 1, p. 136-153, 2009.

PERRENOUD, P. Escola e cidadania: o papel da escola na formação para a democracia. Porto Alegre: Artmed, 2005. 
RANZINI, M. S.; BRYAN, N. A. P. Capacitação e formação para o setor público e os modelos de escola de governo no Brasil. Revista do Serviço Público, Brasília, n. 68, v. 2, p. 417-438, abr./jun. 2017.

SILVA, T. T. Documentos de identidade: uma introdução às teorias do currículo. 2. ed. Belo Horizonte: Autêntica, 2003.

SOUZA, F. S.; ROCHA, M. L. P. C. Academia Real Militar: primeiros Livros utilizados para o Ensino de Matemática Superior no Brasil. REMATEC, n. 26, p. 144-161, set./dez. 2017.

VERGARA, S. C. Estreitando relacionamentos na educação a distância. Cadernos EBAPE, Rio de Janeiro, v. 5, p. 01-08, jan. 2007.

\section{Como referenciar este artigo}

MENDES, V. A. C.; SOUZA, K. R. Tecnologias da informação e comunicação no ensino a distância para a capacitação de servidores públicos. Doxa: Rev. Bras. Psico. e Educ., Araraquara, v. 22, n. 2, p. 442-455, jul./dec. 2020. e-ISSN: 2594-8385. DOI: https://doi.org/10.30715/doxa.v22i2.14242

Submetido em: 18/03/2020

Revisões requeridas: $06 / 06 / 2020$

Aprovado em: 23/07/2020

Publicado em: $31 / 08 / 2020$ 